\title{
ARTICLE
}

\section{Activated Charcoal Pellets as an Innovative Method for Forensic Analysis of Ignitable Liquid Residues from Fire Debris by GC-MS}

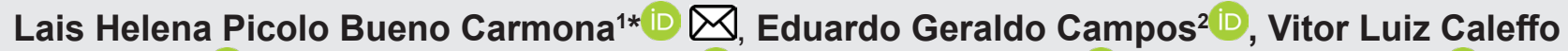

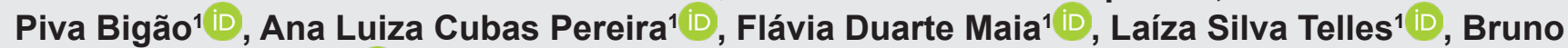 \\ Spinosa De Martinis ${ }^{1}$ iD
}

${ }^{1}$ Departamento de Química, Faculdade de Filosofia, Ciências e Letras de Ribeirão Preto, Universidade de São Paulo, Av. Bandeirantes, 3900, Ribeirão Preto, 14040-901, São Paulo, Brazil

${ }^{2}$ Departamento de Análises Clínicas, Toxicológicas e Bromatológicas, Faculdade de Ciências Farmacêuticas de Ribeirão Preto, Universidade de São Paulo, Av. do Café s/n, Ribeirão Preto, 14040-903, São Paulo, Brazil

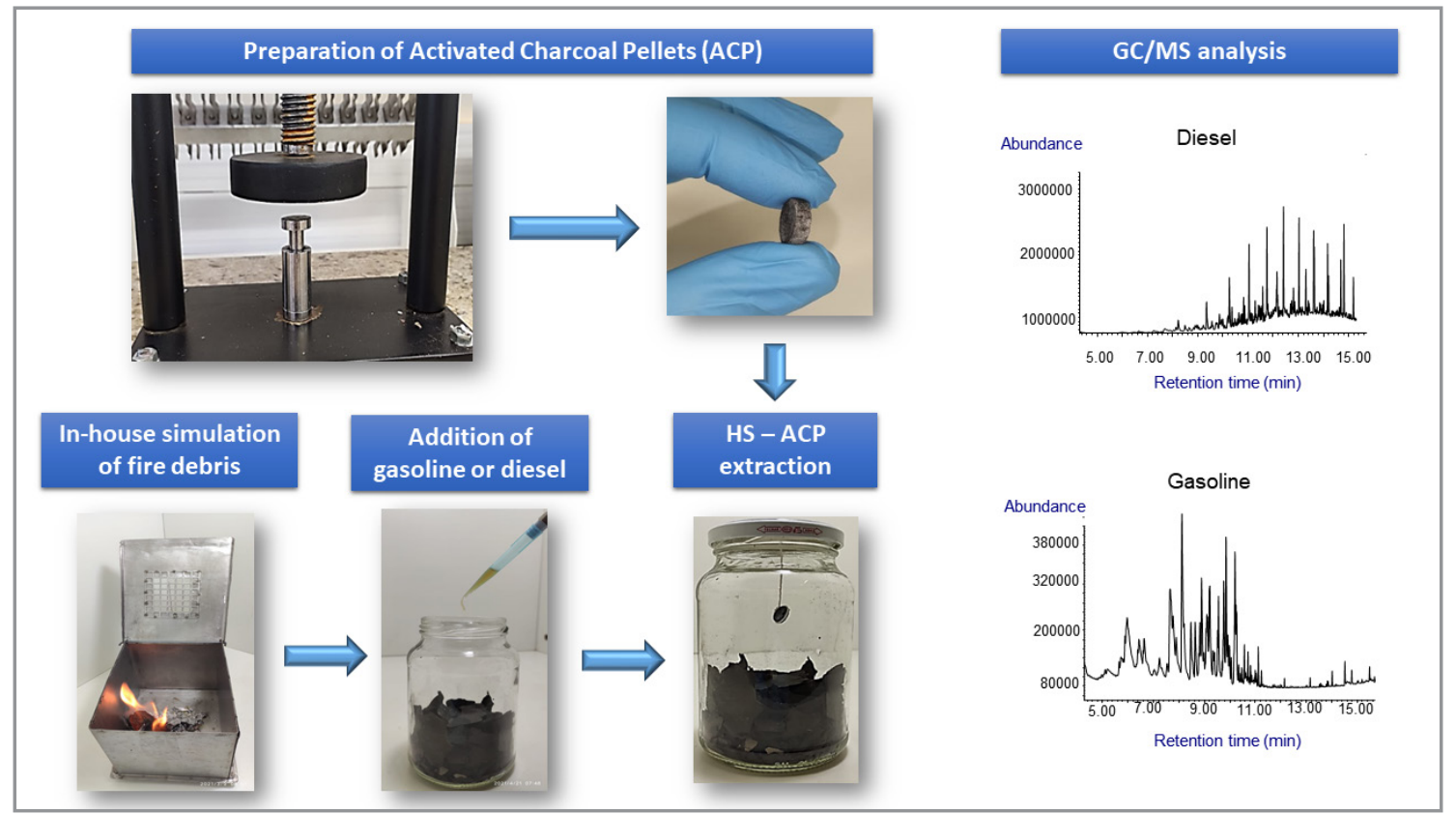

In Forensic Chemistry, evidence collected at a crime scene is of paramount importance for any case to be properly elucidated. Ignitable liquid residues are important chemical evidence in investigations into cases of fire because these substances can be correlated to arson. Here, we describe an innovative technique for sampling and extracting gasoline and diesel from fire debris by using activated charcoal pellets (ACP). $\mathrm{ACP}$ can be an alternative to activated charcoal strips and can be easily produced on the laboratory scale.

Cite: Carmona, L. H. P. B.; Campos, E. G.; Bigão, V. L. C. P.; Pereira, A. L. C.; Maia, F. D.; Telles, L. S.; De Martinis, B. S. Activated Charcoal Pellets as an Innovative Method for Forensic Analysis of Ignitable Liquid Residues from Fire Debris by GCMS. Braz. J. Anal. Chem., 2022, 9 (34), pp 198-209. doi: http://dx.doi.org/10.30744/brjac.2179-3425.AR-62-2021

Submitted 23 April 2021, Resubmitted 25 June 2021, $2^{\text {nd }}$ time Resubmitted 11 August 2021, Accepted 23 August 2021 , Available online 24 September 2021. 
The ACP approach allowed all the target compounds selected for gasoline and diesel fuels to be extracted. Among the six tested extraction conditions, optimal extraction occurred at $100{ }^{\circ} \mathrm{C}$, after $240 \mathrm{~min}$. These preliminary results showed the potential of ACP for detecting gasoline and diesel in fire debris. However, the ACP approach still requires analytical validation, so that its applicability in an authentic forensic setting can be explored.

Keywords: activated charcoal pellets, fire debris, ignitable liquid residues, accelerants, forensic chemistry

\section{INTRODUCTION}

In Forensic Chemistry, evidence collected at a crime scene is of paramount importance for any case to be properly elucidated. During investigations into fires, the presence of ignitable liquid residues (ILR) in fire debris is an important finding that can discriminate between accidental fires and arsons [1-3]. ILR can be intentionally used to induce, to accelerate, and to spread fire $[4,5]$. These accelerants are usually volatile and easily flammable substances [6], such as products of petroleum distillation [2,6,7]. Some common substances include gasoline, diesel, kerosene, turpentine, paint thinners, and alcohols, among others [2,8,9].

Many factors make investigation of arson cases challenging. First, evidence collected in a fire scene may be damaged by the fire itself or by the efforts and measures used to control the fire $[5,8,10]$. For example, powders and foams employed in fire control may lead to interferences [5]. Moreover, given that large amounts of water are frequently used to control fires, ILR might be diluted or even washed [7], which requires sensitive analyses. It is important that any ILR analysis be carefully performed to avoid interpreting that the presence of low levels of ignitable liquids, which may be present in the scene for non-arson-related reasons, is due to arson [11]. The presence of ILR in fire debris does not necessarily confirm an arson because these substances may be present at the scene in normal conditions, especially if we consider that most products derive from petroleum $[11,12]$. Several matrixes including flooring, plastic materials, tires, and shoes may be composed of ignitable liquids [13]. In addition, the composition of IRL may vary, thereby hampering their classification and identification. One example is gasoline, which is commonly reported and easily detected in fire debris but may have variable compositions [13]. Another challenge is the potential degradation of ILR by the soil microbiome [5,13,14]. Microorganisms might interact with petroleum-derived products and degrade important target analytes (e.g., $n$-alkanes) [13], which could lead to a "false-negative" result if an ILR is completely degraded by microorganisms in soil.

During the scene investigation, samples of fire debris are collected and placed in clean containers, protected from leaks (to avoid loss of analyte), and further submitted to forensic laboratories for analysis, especially to search for ILR $[4,6,9,15]$. Information related to the type of ILR present in the sample can support the investigation in identifying the person that was responsible for the criminal fire [8]. Considering all the challenges inherent in this type of analysis, correctly selecting the analytical method and approach is fundamental. Many protocols have been developed and implemented for analysis of ILR in fire debris, especially by the American Society for Testing and Materials (ASTM) [16]. ILR in samples of fire debris are analyzed mainly by gas chromatography coupled to mass spectrometry (GC-MS) $[1,2,5,15]$. GC-MS has been replacing gas chromatography with flame ionization detector (GC-FID) because mass spectrometry (MS) can identify the structure of the compounds present in a sample [6,8]. A sample preparation step is necessary to isolate the ILR and to remove interferents before gas chromatography analysis is performed [1]. Such separation can be achieved via numerous techniques [8,17].

Examples of sample preparation techniques include solvent extraction, direct sampling, passive or dynamic headspace techniques, and solid phase microextraction (SPME) $[4,10,18]$. Regarding solvent extraction, this technique provides fast and simple sample preparation [18] and efficiently extracts heavier substances, with lower vapor pressure [5]. However, this technique requires a large volume for extraction, the amount of solvent must be enough solvent to cover the debris sample completely. Furthermore, solvent extraction is destructive and may be subject to potential interferences from the solvent employed during the extraction [5,18], which can be the same solvent used by the arsonist [18]. 
In turn, headspace techniques offer analytical gains such as easy manipulation, reduced interferences (compared to extractions involving solvents) [1], and fast and non-destructive analyses [18]. Besides that, headspace techniques are good for screening ignitable liquids that may be present in the fire debris, to support technique selection [19]. Passive headspace with a concentration step involves extracting ILR from fire debris samples to an adsorbent material inside a vessel, under heating [1]. Activated charcoal strips (ACS) and SPME are the traditional sorbents in passive headspace approaches [1,9]. Sampling/ extraction based on SPME allows for fast, highly sensitive, and solvent-free analyses [5,6,9]. The fiber in the headspace is exposed for adsorption and the desorption, which occur directly in the GC injector $[5,18]$. Nevertheless, SPME fibers are expensive and frail, have a short lifetime [1], and may generate interferences after reuse $[5,18]$. In the case of passive headspace with ACS, a second step encompassing ILR extraction from the charcoal strips is performed with solvents (e.g., carbon disulfide) $[9,10]$. The ACSbased technique offers advantages like high adsorption capacity for a broad range of substances [5], high sensitivity, easy sample preparation, and possibility of restoring and reanalyzing the remaining materials [1], and ACS are commercially available. However, the technique requires the use of organic solvents and may be time-consuming $[1,5]$.

In this context, we propose an innovative method for extracting ILR from fire debris. The method consists of adsorption/extraction by activated charcoal pellets (ACP) followed by hexane extraction and GC-MS analysis. ACP are an alternative to ACS and have the advantages of reduced cost and rapid preparation in the laboratory, dismissing the need to acquire commercially available strips.

\section{MATERIALS AND METHODS Materials and apparatus}

Reference materials for unleaded gasoline and diesel fuel (5000 $\mathrm{g} \mathrm{mL}^{-1}$ in methanol) were purchased from Sigma-Aldrich (St. Louis, MO, USA) and used during method development. HPLC grade hexane was purchased from Sigma-Aldrich (St. Louis, MO, USA). Gasoline and diesel fuels were acquired from a local store for extraction optimization assays. Analytical grade activated charcoal powder and anhydrous D-glucose were purchased from Synth (Diadema, SP, Brazil) and used to prepare the ACP materials by using a manual press.

\section{ACP preparation and extraction}

The use of charcoal powder as single component and the combination of charcoal powder with other substances (like pellet binder) were tested for ACP preparation. The tested substances included calcium dichloride, silica, and D-glucose as potential pellet binders. Several proportions of activated charcoal powder and binders were tested, including 1:1, 1:5, 1:10, 1:15, and 1:16 $(\mathrm{m} / \mathrm{m})$. After the best conditions to prepare the pellets were established, the powder materials were inserted into a cylindrical mold, manually pressed, and held in the supporting mold for five minutes. The pellets were further removed and heated at $60{ }^{\circ} \mathrm{C}$ for $12 \mathrm{~h}$ to remove potential contaminants. 


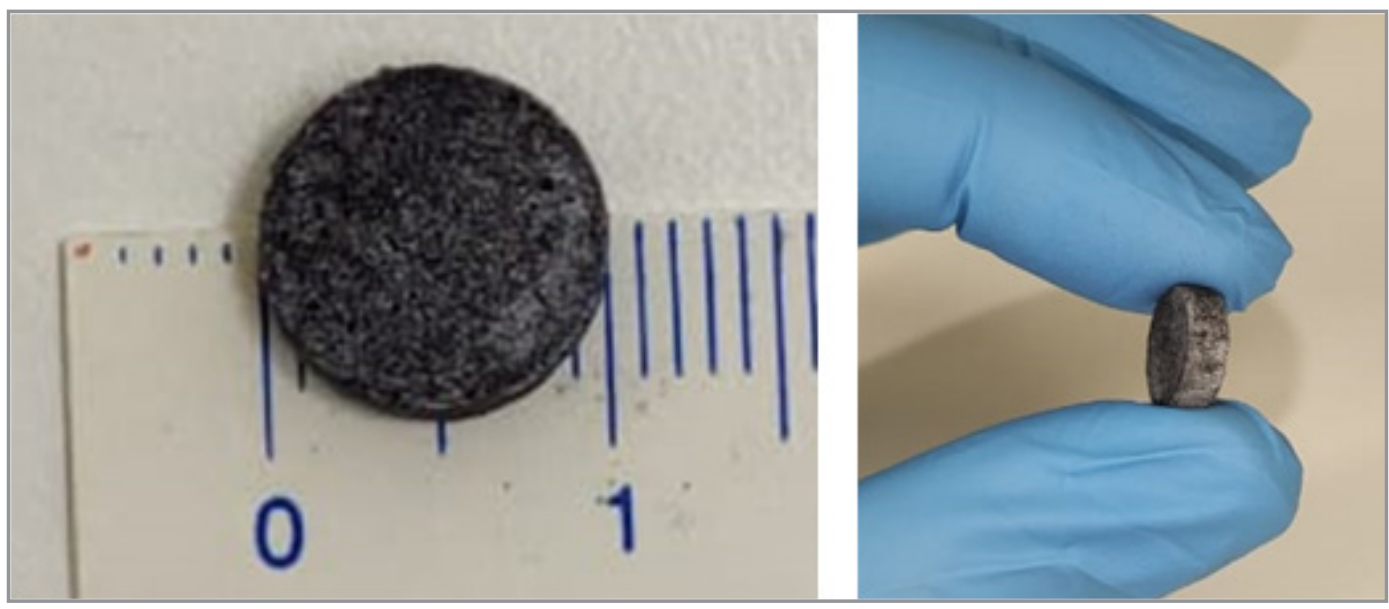

Figure 1. General aspects of the ACP.

Fire debris was simulated on the laboratory scale by burning cotton fabric and paper through direct flame contact. A portion of the simulated samples was placed in the bottom of the glass recipients, and 400 $\mu \mathrm{L}$ of pure gasoline and diesel were added to the top of the debris (except for blank extraction, to which no fuels were added). The ACP were attached to the glass container lid through a 1-mm-thick cotton string. The entire apparatus was placed in the laboratory oven at $100^{\circ} \mathrm{C}$ for $240 \mathrm{~min}$ (Figure 2).

A

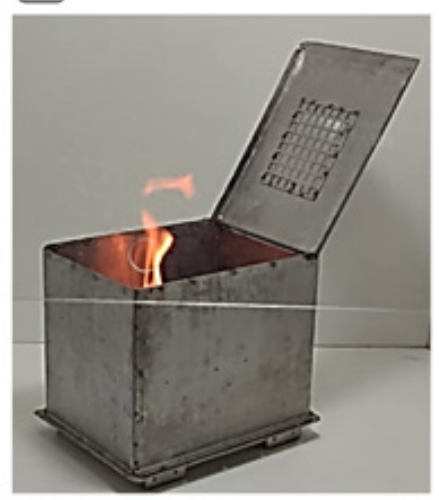

B

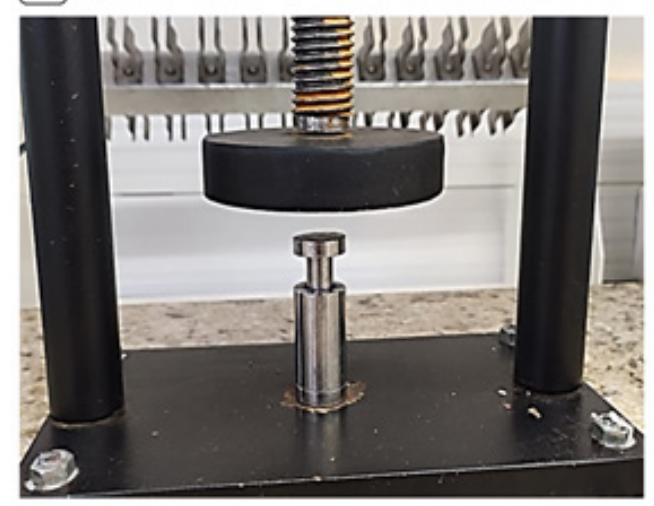

C

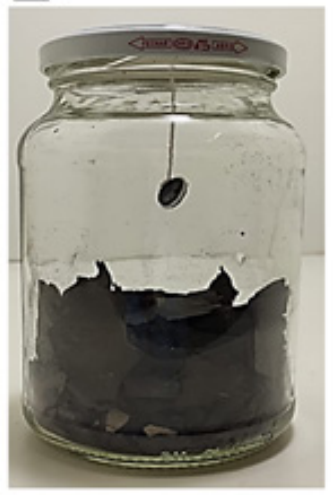

Figure 2. A: Process for burning materials to simulate fire debris. B: The manual press where the pellets were fabricated and the cylindrical mold and C: Glass vial containing the simulated fire debris and the pellets suspended in the headspace.

After the samples were heated, the pellets were removed from the glass containers and transferred to glass tubes, and $1 \mathrm{~mL}$ of hexane was added to the tubes for extraction. Solvent extraction was performed by horizontal agitation at $120 \mathrm{rpm}$ for $5 \mathrm{~min}$. Then, $10 \mu \mathrm{L}$ of the extract was collected, added to a $1.5 \mathrm{~mL}$ clean glass vial, diluted with $50 \mu \mathrm{L}$ of hexane, and injected into the GC-MS. Six different extraction assays were accomplished, in duplicate, according to Table I. The experiments involved two glass containers with debris, containing the pellet suspended with gasoline and diesel, as described. 
Table I. Different temperatures and times tested for gasoline and diesel extraction from debris by using ACP

\begin{tabular}{ccc}
\hline Condition & Temperature $\left({ }^{\circ} \mathbf{C}\right)$ & Time $(\min )$ \\
\hline 1 & 50 & 240 \\
2 & 60 & 155 \\
3 & 60 & 325 \\
4 & 75 & 120 \\
5 & 75 & 240 \\
6 & 100 & 240 \\
Blank & 100 & 240 \\
\hline
\end{tabular}

\section{Instrumentation}

Analyses were carried out on an Agilent 7890A gas chromatograph equipped with an Agilent 7683 automatic sampler and coupled to an Agilent 5975C mass spectrometer (Agilent Technologies ${ }^{\circledR}$, Santa Clara, CA, USA). Chromatographic separation was performed on a DB-5MS fused silica capillary column (5\%-phenyl)-methylpolysiloxane phase $(30 \mathrm{~m} \times 0.25 \mathrm{~mm} \times 0.25 \mu \mathrm{m})$ (Agilent Technologies ${ }^{\circledR}$, Santa Clara, CA, USA). Helium was used as carrier gas at a flow rate of $1 \mathrm{~mL} \mathrm{~min}^{-1}$. The injector temperature was maintained at $260^{\circ} \mathrm{C}$. The sample was introduced in the split injection mode. The following column temperature program was applied: initial temperature of $50{ }^{\circ} \mathrm{C}$ with holding time of 5 min, followed by an

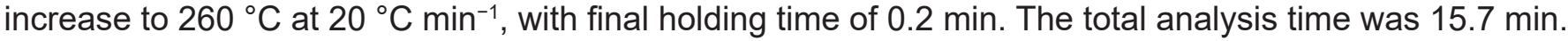
The temperatures of the mass spectrometer interface, source, and quadrupole were 230 and $150{ }^{\circ} \mathrm{C}$, respectively. The mass spectrometer was operated in the full scan mode.

\section{Selection of target compounds in gasoline and diesel}

To select the target compounds in gasoline and diesel for further monitoring during chemical analysis, the gasoline and diesel fuels were initially analyzed. The fuels were diluted in hexane $\left(5000 \mu \mathrm{gL}^{-1}\right)$ and analyzed by GC-MS in the full scan mode. The chromatographic peaks with the smallest width and highest abundance were selected, and their mass spectral profile was manually compared against the NIST library (NIST MS Search 2.0, 2009).

\section{Qualitative ACP extraction evaluation}

The ACP extraction efficiency was qualitatively assessed by verifying the volume of gasoline and diesel that was recovered and by identifying the target compounds. For this test, the ACP were attached to a polyamide string $(0.25 \mathrm{~mm}$ diameter) in a $20 \mathrm{~mL}$ headspace vial, in the absence of debris. Headspace vials were used to standardize the extraction given that they have better seal capability, thereby avoiding losses by evaporation. The polyamide string was preferred to a cotton string because the former has no pores, and its diameter is smaller. Twelve samples (six with gasoline and six with diesel) were prepared and added at the bottom of the vials, in different amounts $(1,5,10,20,30$, and $40 \mu \mathrm{L})$. Blank samples consisting of the ACP suspended in the vial without, gasoline, or diesel were prepared and extracted, to evaluate any possible potential interferents from the vial or the polyamide string. The vials were incubated in a laboratory oven at $100{ }^{\circ} \mathrm{C}$ for $240 \mathrm{~min}$. Gasoline and diesel were extracted from the ACP as previously described. 


\section{RESULTS AND DISCUSSION \\ ACP preparation}

Using only charcoal powder to prepare the ACP gave poor results. When we pressed the charcoal powder, it did not agglutinate into pellets satisfactorily, and the pellet quickly disintegrated into the powder form. To address this problem, we tested three substances as pellet binder: calcium dichloride, silica, and D-glucose. The condition that provided more physically resistant pellets (i.e., pellets that did not disintegrate when they were removed from the mold or attached to the cotton string) was achieved by combining activated charcoal powder and D-glucose, as binder, at a 1:16 $(\mathrm{m} / \mathrm{m})$ ratio. Therefore, to prepare the ACP, we adopted a total mass of $0.3 \mathrm{mg}$ of activated charcoal powder and D-glucose $(1: 16 \mathrm{~m} / \mathrm{m})$ for the study.

\section{GC-MS analysis of fire debris by using ACP}

Figures 3 and 4 show the total ion chromatogram of the analysis of gasoline and diesel fuels, in hexane. The identified peaks are numbered from 1 to 6 for gasoline and from 7 to 14 for diesel. Tables II and III list the identities of the compounds selected for the targeted analyses.

Table II. Selected target compounds for gasoline

\begin{tabular}{cccl}
\hline Number & $\mathbf{m} / \mathbf{z}$ & Retention Time $(\mathbf{m i n})$ & Target Compound \\
\hline 1 & $105,120,91$ & 8.117 & 1-ethyl-3-methylbenzene \\
2 & $119,105,134$ & 8.884 & 1,4-diethylbenzene \\
3 & $119,134,91$ & 9.548 & 1,2,3,5-tetramethylbenzene \\
4 & $117,132,115$ & 9.754 & 1-methyl-2-(2-propenyl)benzene \\
5 & $117,132,115$ & 9.84 & 1-methyl-4-(2-propenyl)benzene \\
6 & $131,146,115$ & 10.191 & 2,3-dihydro-4,7-dimethyl-1H-indane \\
\hline
\end{tabular}

Table III. Selected target compounds for diesel

\begin{tabular}{cccl}
\hline Number & $\boldsymbol{m} / \mathbf{z}$ & Retention Time $(\mathbf{m i n})$ & Target Compound \\
\hline 7 & $57,43,41$ & 9.332 & Undecane \\
8 & $57,43,71$ & 10.24 & Dodecane \\
9 & $57,43,41$ & 11.023 & Tridecane \\
10 & $57,43,41$ & 11.731 & Tetradecane \\
11 & $57,43,41$ & 12.39 & Pentadecane \\
12 & $57,43,41$ & 13.011 & Hexadecane \\
13 & $57,43,41$ & 13.594 & Heptadecane \\
14 & $57,43,41$ & 14.145 & Octadecane \\
\hline
\end{tabular}




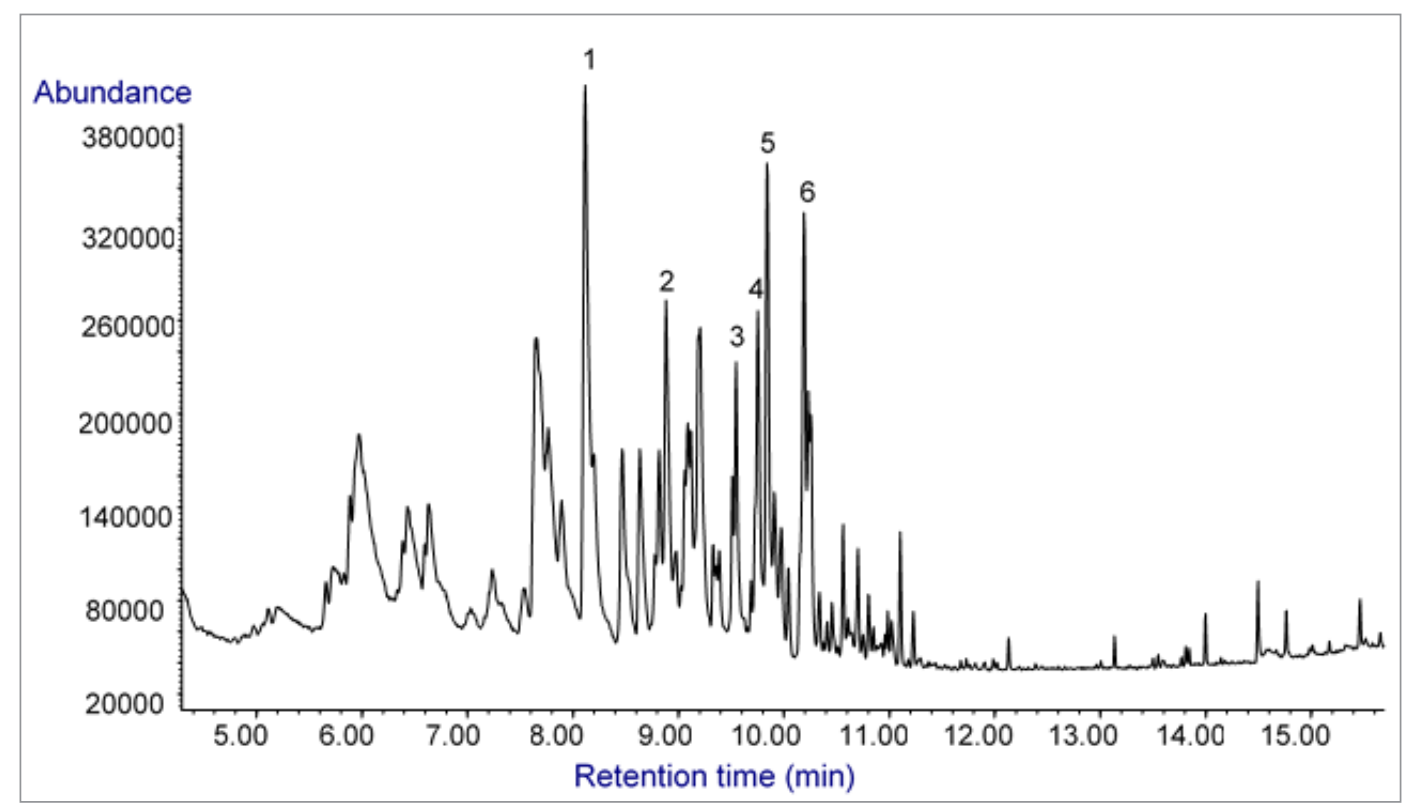

Figure 3. Chromatogram of $5000 \mu \mathrm{gL}^{-1}$ gasoline, in hexane. The identified compounds are numbered and listed in Table II.

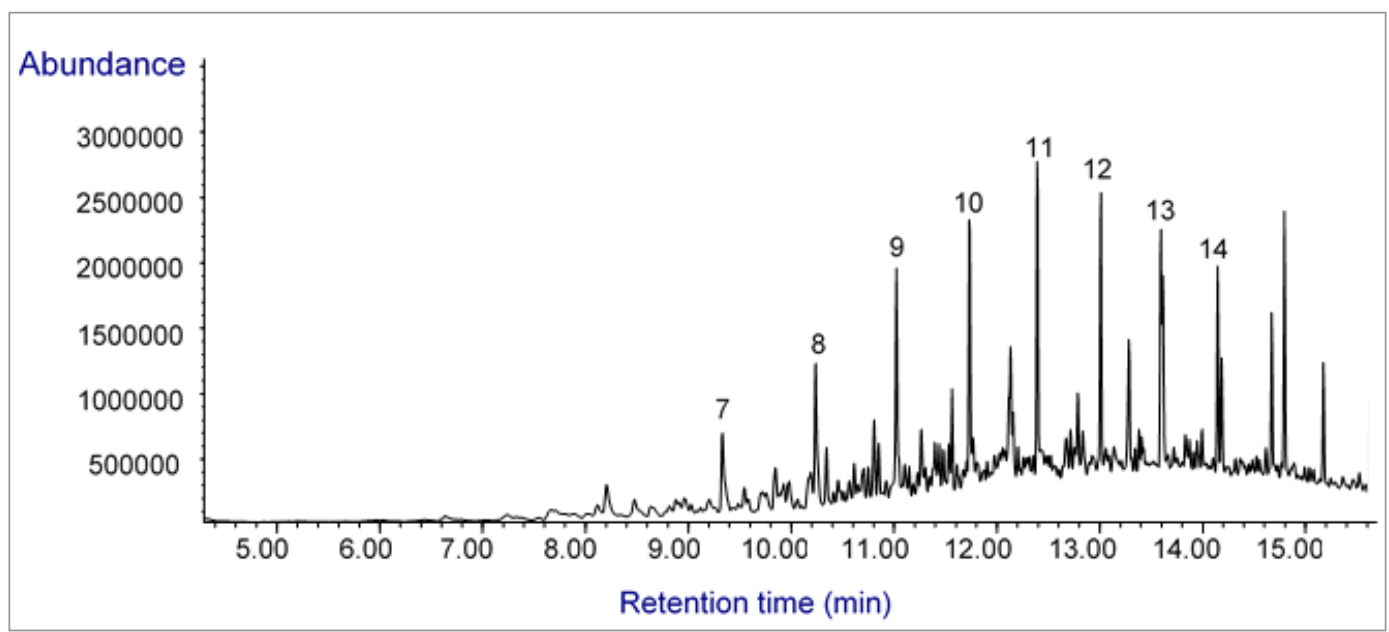

Figure 4. Chromatogram of $5000 \mu \mathrm{g} \mathrm{mL}^{-1}$ diesel, in hexane. The identified compounds are numbered and listed in Table III.

\section{Evaluation of the optimal extraction conditions}

After the target compounds were properly selected, we tested the extraction of gasoline and diesel fuels by the ACP to establish the conditions that would provide the best signal for each compound. We used a mixture of gasoline and diesel to optimize the extraction conditions for both fuels by considering the situation in which these two liquids would be found in a sample of fire debris. We randomly selected the extraction times to be tested in the experiments by considering extractions no longer than $6 \mathrm{~h}$, to enable time-effective analyses. We tested each condition in duplicate and, to avoid carryover, we injected $1 \mu \mathrm{L}$ of hexane into the GC-MS between each chromatographic run. Initially, we tested temperatures higher than $100{ }^{\circ} \mathrm{C}$ for extraction (e.g., 105,135 , and $150^{\circ} \mathrm{C}$ ). However, at 135 and $150{ }^{\circ} \mathrm{C}$, the pellets melted down. The results at $105^{\circ} \mathrm{C}$ resembled the results obtained at $100^{\circ} \mathrm{C}$, so we conducted the tests at 100 ${ }^{\circ} \mathrm{C}$ to ensure that the pellets would not deform or melt, thereby avoiding poor or no gasoline and diesel extraction. 
Figures 5 and 6 illustrate the chromatogram peak areas obtained for each analyte, in each of the tested conditions. In the graph, the area values are the average area of the duplicate experiments in the same conditions for each compound; the standard deviation of these measures is shown. The numbers refer to the target compound monitored for gasoline and diesel according to Tables II and III, respectively.

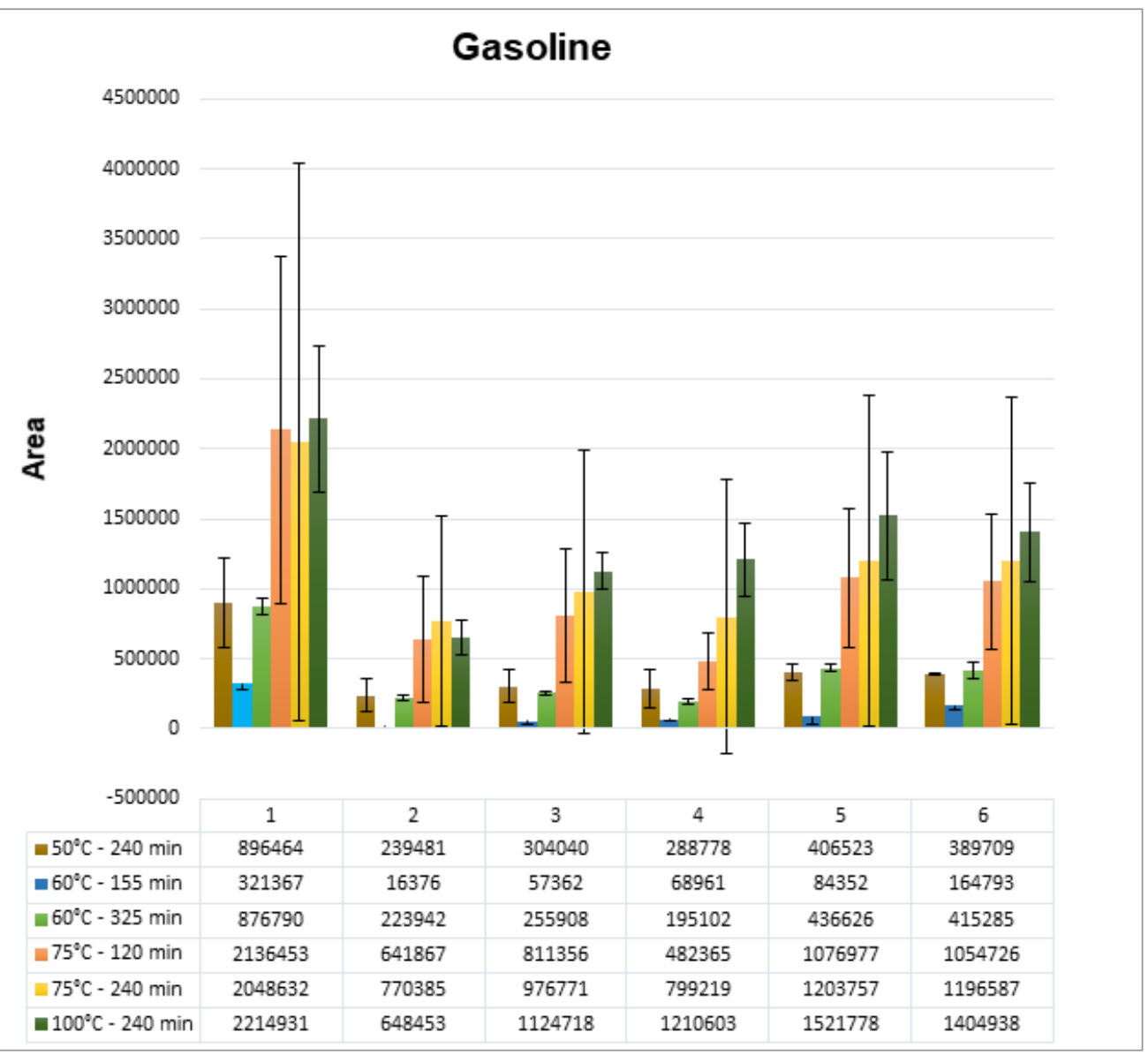

Figure 5. Response (peak areas) of each compound in gasoline (listed in Table II) obtained at different temperatures and extraction times.

The optimal extraction conditions for both gasoline and diesel (based on the best signal areas of each target compound) were $100{ }^{\circ} \mathrm{C}$ and 240 min (dark green bars). This temperature was the highest tested temperature at which the pellet maintained its physical stability, but heat could lead to interferences [20]. Therefore, we submitted a blank sample consisting of the glass container with debris and the pellet suspended without gasoline or diesel fuels to extraction at $100{ }^{\circ} \mathrm{C}$ for $240 \mathrm{~min}$ to investigate possible whether heat generated interferents from the pellets, glass container, or debris. We found no interferents in the blank chromatogram. Condition number 5 (yellow bars) resembled condition number 6 (dark green bars) for both gasoline and diesel, with the target compounds showing larger peak areas in condition 6. However, the standard deviation observed for condition 5 was higher if compared to condition 6 , suggesting better (considering the higher areas) and more reliable/robust results under condition 6 . We achieved the worst results for condition number $2\left(60^{\circ} \mathrm{C}\right.$ for $155 \mathrm{~min}$ - blue bars), which gave reduced peak areas for all the compounds. In general, longer extraction time increased the peak area of each target analyte, except for compound 1 (1-ethyl-3-methylbenzene) in condition number $5\left(75^{\circ} \mathrm{C}\right.$ for 240 min orange bars). For example, extractions performed at $50{ }^{\circ} \mathrm{C}$ for $240 \mathrm{~min}$ (brown bars) produced large peak areas compared to extractions conducted at $60{ }^{\circ} \mathrm{C}$ for $155 \mathrm{~min}$ (blue bars) even though higher temperatures provided 
better responses (in terms of peak areas). In this sense, longer extraction times were positive factors for the overall quality of extraction with the ACP. However, further studies are necessary to understand the mechanism of analyte adsorption onto the ACP: some compounds were poorly adsorbed on the pellets, which could also explain the low recoveries in these tested conditions.

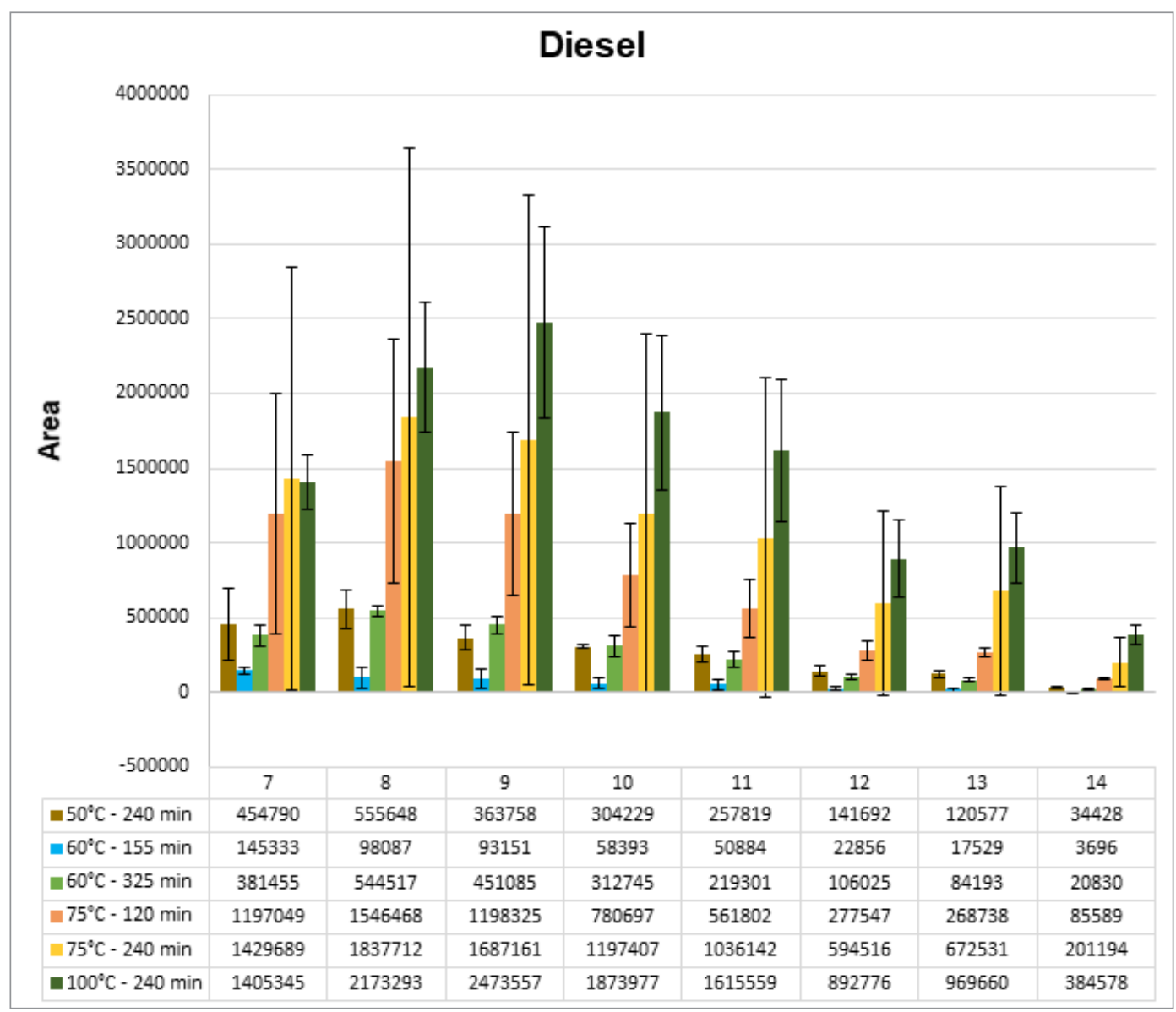

Figure 6. Response (peak areas) of each diesel compound (listed in Table III) obtained at different temperatures and extraction times.

We assessed extraction efficiency at the optimal condition $\left(100{ }^{\circ} \mathrm{C}, 240 \mathrm{~min}\right)$ by extracting a set of samples using headspace vials without debris and separately adding different volumes of gasoline and diesel at the bottom of the vial $(1,5,10,20,30$, and $40 \mu \mathrm{L})$. We analyzed the chromatograms and searched for the target compound. According to the standard ASTM E1618-11 (2011), "an adequate chromatogram with sufficient data for comparison work is one in which the peaks of interest are 50 to $100 \%$ of full scale" [21]. On the basis of this information and by considering only the chromatograms that had all the target compounds, we found that the limit volume of extraction was 20 and $40 \mu \mathrm{L}$ for diesel and gasoline, respectively. The volumes of 20 and $40 \mu \mathrm{L}$ represent the quantities present in the vial, recovered by the pellet, which resulted in the positive identification of diesel and gasoline, respectively, after extraction process.

\section{Comparison between ACP and other sampling/extraction methods}

Table IV compares the extraction efficiency/sensitivity findings of this study and of other studies is provided, encompassing traditional extraction methods standardized by ASTM [18,19,22-24] and new materials $[7,15,25]$, such as ACP. The headspace technique is the least sensitive among all the traditional 
methods [18], and volumes below $10 \mu \mathrm{L}$ may not be sufficient for recovery and extraction [19]. However, the efficiency/sensitivity seems to be controversial [18], with limit volumes of extraction ranging from 1 to $10 \mu \mathrm{L}$ [18], but also being as low as $0.1 \mu \mathrm{L}$ [22]. Being vapor concentration-based techniques, ACS and SPME are more sensitive than the headspace and solvent extraction techniques, [18]. Moreover, ACS and SPME are highly sensitive, reaching volumes lower than $0.1 \mu \mathrm{L}$ [18]. As for new adsorbent materials, some exhibit limit volumes of extraction in line with the results reached with the ACP technique developed in this study. Hydrophobic pads and ACP produce closer results, but the former is more efficient in the recovery of lighter compounds [7], whereas ACP is more efficient for heavier compounds. A major advantage of the ACP approach proposed in this study is the possibility of rapidly producing adsorbents in the laboratory, at low cost.

Table IV. Comparison between the efficiency of the ACP technique and some traditional techniques and new adsorbent materials

\begin{tabular}{|c|c|c|c|c|}
\hline & Reference & Methods & Limit volume of extraction & Compounds \\
\hline 1 & [19] & Headspace & Above $10 \mu \mathrm{L}$ & $\begin{array}{l}\text { Better for low molecular } \\
\text { weight compounds }\end{array}$ \\
\hline 2 & {$[18,22]$} & Solvent extraction & $1 \mu \mathrm{L}[22] / 10 \mu \mathrm{L}[18]$ & $\begin{array}{l}\text { Better for high molecular } \\
\text { weight compounds }\end{array}$ \\
\hline 3 & [23] & ACS & $0.1 \mu \mathrm{L}$ & All range of compounds \\
\hline 4 & [24] & SPME & $0.1 \mu \mathrm{L}$ & All range of compounds \\
\hline 5 & [15] & $\begin{array}{l}\text { Limestone and British } \\
\text { Fuller's earth; } 10: 1 \mathrm{w} / \mathrm{w}\end{array}$ & Not specified & All range of compounds \\
\hline 6 & [7] & Hydrophobic Pads & $10 \mu \mathrm{L}(\mathrm{A})$ and $25 \mu \mathrm{L}(\mathrm{B})$ & $\begin{array}{l}\text { A: heavier and B: lighter } \\
\text { (six atoms of carbon or } \\
\text { less) compounds }\end{array}$ \\
\hline 7 & [25] & $\begin{array}{l}\text { Activated Charcoal } \\
\text { Cloth (ACC) }\end{array}$ & $10 \mu \mathrm{L}$ & $\begin{array}{l}\text { Lighter fluid, camp fuel, } \\
\text { thinners, lamp oil, and } \\
\text { kerosene }\end{array}$ \\
\hline 8 & This study & $\mathrm{ACP}$ & $20 \mu \mathrm{L}(\mathrm{C})$ and $40 \mu \mathrm{L}(\mathrm{D})$ & C: diesel and D: gasoline \\
\hline
\end{tabular}

\section{CONCLUSIONS}

ACP are a promising alternative for extracting gasoline and diesel from fire debris. This technique allowed all the target compounds selected from gasoline and diesel and added to the debris to be detected. ACP have two main advantages: reduced costs and possibility of preparing the pellets in a laboratory setting, dismissing the need for purchasing an adsorbent. The goal of this study was to report the preliminary development of this new approach, and we have shown its promising applicability in fire debris analyses. However, further studies are still needed to validate this method for routine applications, to understand the adsorption mechanisms occurring on the ACP and to evaluate analytical parameters such as recovery, limit of detection, and selectivity. These further studies will be essential to explore and to discuss other advantages and limitations of the method.

\section{Conflicts of interest}

The authors declare no conflicts of interest.

\section{Acknowledgment}

This study was financed in part by the Coordenação de Aperfeiçoamento de Pessoal de Nível Superior - Brasil (CAPES) - Finance Code 001 (doctoral fellowship and Pro-Forenses Grant - N. 25/2014). 


\section{REFERENCES}

1. Fabritius, M. M.; Broillet, A.; König, S.; Weinmann, W. Forensic Sci. Int., 2018, 289, pp 232-237 (https:// doi.org/10.1016/j.forsciint.2018.05.048).

2. Ferreiro-González, M.; Barbero, G.; Palma, M.; Ayuso, J.; Álvarez, J.; Barroso, C. Sensors, 2016, 16 (5), 695 (https://doi.org/10.3390/s16050695).

3. Choi, S.; Yoh, J. J. Spectrochim. Acta - Part B At. Spectrosc., 2017, 134, pp 75-80 (https://doi. org/10.1016/j.sab.2017.06.010).

4. Smith, R. W.; Brehe, R. J.; Mcllroy, J. W.; McGuffin, V. L. Forensic Chem., 2016, 2, pp $37-45$ (https:// doi.org/10.1016/j.forc.2016.08.005).

5. Martín-Alberca, C.; Ortega-Ojeda, F. E.; García-Ruiz, C. Anal. Chim. Acta, 2016, 928, pp 1-19 (https:// doi.org/10.1016/j.aca.2016.04.056).

6. Dolan, J. Anal. Bioanal. Chem., 2003, 376 (8), pp 1168-1171 (https://doi.org/10.1007/s00216-0031890-5).

7. Totten, V.; Willis, J. Forensic Sci. Int. , 2020, 312, 110309 (https://doi.org/10.1016/j.forsciint.2020.110309).

8. Cacho, J. I.; Campillo, N.; Aliste, M.; Viñas, P.; Hernández-Córdoba, M. Forensic Sci. Int., 2014, 238, pp 26-32 (https://doi.org/10.1016/j.forsciint.2014.02.006).

9. Kabir, A.; Holness, H.; Furton, K. G.; Almirall, J. R. TrAC - Trends Anal. Chem., 2013, 45, pp 264-279 (https://doi.org/10.1016/j.trac.2012.11.013).

10. Sinkov, N. A.; Sandercock, P. M. L.; Harynuk, J. J. Forensic Sci. Int., 2014, 235, pp 24-31 (https://doi. org/10.1016/j.forsciint.2013.11.014).

11. Abel, R. J.; Zadora, G.; Sandercock, P. M. L.; Harynuk, J. J. Separations, 2018, 5 (4), pp 1-18 (https:// doi.org/10.3390/separations5040058).

12. St. Pierre, K. A.; Desiderio, V. J.; Hall, A. B. Forensic Sci. Int., 2014, 240, pp 137-143 (https://doi. org/10.1016/j.forsciint.2014.02.017).

13. Baerncopf, J.; Hutches, K. Forensic Sci. Int., 2014, 244, pp e12-e20 (https://doi.org/10.1016/j. forsciint.2014.08.006).

14. Turner, D. A.; Pichtel, J.; Rodenas, Y.; McKillip, J.; Goodpaster, J. V. Forensic Sci. Int., 2015, 251, pp 69-76 (https://doi.org/10.1016/j.forsciint.2015.03.013).

15. Hall, S.; White, G.; Gautam, L. J. Anal. Appl. Pyrolysis, 2016, 122, pp 304-314 (https://doi.org/10.1016/j. jaap.2016.09.012).

16. Stauffer, É.; Lentini, J. J. Forensic Sci. Int., 2003, 132 (1), pp 63-67 (https://doi.org/10.1016/S03790738(02)00459-0).

17. Grafit, A.; Muller, D.; Kimchi, S.; Avissar, Y. Y. Forensic Sci. Int., 2018, 292, pp 138-147 (https://doi. org/10.1016/j.forsciint.2018.09.004).

18. Stauffer, E.; Dolan, J. A.; Newman, R. (Eds.) Fire Debris Analysis. Elsevier, Burlington, MA, 2008, Chapter 11: Extraction of Ignitable Liquid Residues from Fire Debris, pp 377-439 (https://doi. org/10.1016/B978-012663971-1.50015-4).

19. ASTM International. ASTM E1388-12. Standard Practice for Sampling of Headspace Vapors from Fire Debris Samples. West Conshohocken, USA: ASTM, 2012.

20. Stauffer, E. Sources of interference in fire debris analysis. In: Daeid, N. N. (Ed.). Fire Investigation. CRC Press, Boca Raton, 2004, pp 191-226.

21. ASTM International. ASTM E1618-11. Standard Test Method for Ignitable Liquid Residues in Extracts from Fire Debris Samples by Gas Chromatography-Mass Spectrometry. West Conshohocken, USA: ASTM, 2011.

22. ASTM International. ASTM E1386-15. Standard Practice for Separation of Ignitable Liquid Residues from Fire Debris Samples by Solvent Extraction. West Conshohocken, USA: ASTM, 2015.

23. ASTM International. ASTM E1412-07. Standard Practice for Separation of Ignitable Liquid Residues from Fire Debris Samples by Passive Headspace Concentration With Activated Charcoal. West Conshohocken, USA: ASTM, 2007. 
24. ASTM International. ASTM E2154-15a. Standard Practice for Separation and Concentration of Ignitable Liquid Residues from Fire Debris Samples by Passive Headspace Concentration with Solid Phase Microextraction (SPME). West Conshohocken, USA: ASTM, 2015.

25. Sandercock, P. M. L. Can. Soc. Forensic Sci. J., 2016, 49 (4), pp 176-188 (https://doi.org/10.1080/00 085030.2016.1189226). 